\title{
DOSE-RESPONSE STUDY: MGSO4 IN CARDIOVASCULAR RESPONSES AFTER LARYNGOSCOPY \& ENDOTRACHEAL INTUBATION
}

AUTHORS:

Kamran Montazeri PhD MD, associated professor of anesthesiology; M Falah PhD MD

\author{
AFFILIATION: \\ Department of Anesthesiology, Isfahan University of Medical Sciences, Isfahan, IRAN
}

\section{INTRODUCTION:}

The effects of pre-treatment with mangnesium on cardiovascular responses associated with intubation were studied previously.In this dose- response study we wanted to find optimal dose of magnesium that causes in a decreased responses after larngoscopy \& endotracheal intubation .

\section{METHODS:}

After approval of ethics committee of Isfahan university. In a double-blind, randomized clinical trial,120 ASA-1 patient in ages between 15-50 years old, candidates of elective surgery were selected and classified in 6 groups(20 patients in each). The pulse rate and arterial blood pressure were measured and recorded at 5 min before took any drugs and then according to different groups magnesium sulphate $(10,20,30,40,50 \mathrm{mg} / \mathrm{kg})$ and lidocaine $(1.5 \mathrm{mg} / \mathrm{kg})$.

The induction of anesthesia was same in all groups and the pulse rate and arterial blood pressure were measured and recorded at just before intubation and also at 1, 3, and $5 \mathrm{~min}$ after intubation (before surgical incision).

Statistical analysis was performed by use of ANOVA, post Hoc test (Duncan),Pearson correlation, and Chi square tests.

\section{RESULTS :}

The groups were well matched for demographic data and no statistically significant differences were found between groups in age, weight, sex and surgical position . After laryngoscopy and intubation statistically significant changes as percent base values were found between magnesium groups and lidocaine $(\mathrm{p}<0.05)$ but between magnesium groups was not significant $(\mathrm{p}>0.05)$.

In group of C ( $30 \mathrm{mg} / \mathrm{kg}$ mgso4) changes in heart and mean blood pressure was lower from another groups. TOF at minute 45 after induction of anesthesia in all groups has been no statistically significant differences $(\mathrm{p}>0.05)$.

Complications of magnesium, like hypotension, arrhythmia, nausea, sweating, flashing and hot sense has been no significant change between all groups $(p>0.05)$.

\section{DISCUSSION:}

There were no statistically significant differences in blood pressure,pulse rate,TOF and complications in and between groups who received magnesium but the significant differences were seen between magnesium and lidocaine in those parameters.

We concluded that pretreatment with different doses of magnesium sulfate have a safe decreasing effect on cardiovascular responses, that were more effective then pretreatment.

\section{REFERECES:}

1- British J of Anesth . 89 :594-598. 